\title{
Radiation Use Efficiency of Cotton in Contrasting Environments
}

\author{
Evangelos D. Gonias ${ }^{1}$, Derrick M. Oosterhuis ${ }^{1}$, Androniki C. Bibi ${ }^{1}$, Bruce A. Roberts ${ }^{2}$ \\ ${ }^{1}$ Department of Crop, Soil, and Environmental Sciences, University of Arkansas, Fayetteville, USA; ${ }^{2}$ Plant Science Department, \\ California State University, Fresno, USA. \\ Email: egonias@hotmail.com
}

Received January $20^{\text {th }}, 2012$; revised February $17^{\text {th }}, 2012$; accepted March $8^{\text {th }}, 2012$

\begin{abstract}
Crop growth and yield varies among locations due to differences in environmental parameters, such as temperature, relative humidity, solar radiation and vapor pressure deficit. Previous research has shown that increasing vapor pressure deficit has a negative effect on radiation use efficiency of many crops. In this study, the radiation use efficiency of cotton (Gossypium hirsutum L.) grown in two contrasting production environments, Arkansas and California, was evaluated for two years, in 2006 and 2007. Temperature, relative humidity, vapor pressure deficit and photosynthetically active radiation were recorded at both locations. Although the crop in California accumulated more dry matter during the period of the study, the radiation use efficiency was found to be lower compared to Arkansas. Radiation use efficiency for the Arkansas and California locations was estimated at 2.060 and $1.518 \mathrm{~g} \cdot \mathrm{MJ}^{-1}$ of intercepted photosynthetically active radiation, respectively. The higher productivity observed in California can be attributed to larger amounts of incident and intercepted radiation in this location. Radiation use efficiency of cotton was estimated to decrease with increasing vapor pressure deficit by a slope of $-0.47 \mathrm{~g} \cdot \mathrm{MJ}^{-1} \cdot \mathrm{kPa}^{-1}$.
\end{abstract}

Keywords: Dry Matter; Environment; Gossypium hirsutum L.; Light Interception; Radiation Use Efficiency; Vapor Pressure Deficit

\section{Introduction}

Biomass accumulation by a crop depends on its ability to intercept and utilize solar radiation. The amount of dry matter produced per unit of intercepted radiation $\left(\mathrm{g} \cdot \mathrm{MJ}^{-1}\right)$ is termed the radiation use efficiency (RUE) of the crop. Average values of RUE range from 2.0 to 3.0 and 3.0 to $4.0 \mathrm{~g} \cdot \mathrm{MJ}^{-1}$ of absorbed photosynthetically active radiation (PAR) for $\mathrm{C}_{3}$ and $\mathrm{C}_{4}$ plants, respectively $[1,2]$. For cotton (Gossypium hirsutum L.), estimated values of RUE for the cultivars Siokra 1 - 4 (okra leaf) and Deltapine 90 (normal-leaf) ranged from 1.70 to $1.92 \mathrm{~g} \cdot \mathrm{MJ}^{-1}$ of intercepted photosynthetically active radiation (PAR) across two experiments in Australia [3]. Whereas, Rosenthal and Gerik reported RUE values of the cotton cultivars Acala SJ-2, Deltapine 50, and Tamcot CD3H in Texas of $1.46,1.60$, and $1.31 \mathrm{~g} \cdot \mathrm{MJ}^{-1}$ of intercepted PAR, respectively [4]. In a $\mathrm{CO}_{2}$ enriched environment, RUE of cotton increased from $1.56 \mathrm{~g} \cdot \mathrm{MJ}^{-1}$ at $370 \mathrm{ppm} \mathrm{CO}_{2}$ to $1.97 \mathrm{~g} \cdot \mathrm{MJ}^{-1}$ of intercepted PAR at $550 \mathrm{ppm} \mathrm{CO}_{2}[5]$.

Environmental conditions have a direct effect on crop growth. Temperatures above $33^{\circ} \mathrm{C}$ for cotton have been shown to decrease net carbon assimilation [6]. In addition, peanut (Arachis hypogaea L.) grown with contrast- ing night temperatures in field and glasshouse studies, showed differences in RUE [7]. The amount and composition of incident radiation also appears to have an effect on RUE. Bange et al. suggested that sunflower (Helianthus annuus L.) grown under plastic films, with reduced amount of incident and increased proportion of diffuse radiation, produced biomass similar to unshaded plants by increasing their RUE [8]. Theoretical estimates for soybean [Glycine max (L.) Merr.] and maize (Zea mays L.) showed RUE to increase as the total amount of radiation decreased and the proportion of diffuse radiation increased [9].

An environmental factor that is not always taken into consideration in analyzing crop growth is the vapor pressure deficit (VPD) of the air. Vapor pressure deficit $(\mathrm{kPa}) \mathrm{can}$ be defined as the difference between the amount of moisture in the air (vapor pressure) at saturation and at a specific condition [10]. Vapor pressure deficit can be estimated from psychrometric charts or calculated using air temperature and relative humidity.

High VPD ( $>1 \mathrm{kPa}$ ) was shown to decrease leaf photosynthesis in wheat (Triticum aestivum L.) [11]. Similarly, RUE has been reported to decrease as VPD in- 
creases. For sorghum (Sorghum bicolor L.) and corn, RUE based on PAR decreased with increasing VPD with a slope of -0.65 and $-0.85 \mathrm{~g} \cdot \mathrm{MJ}^{-1} \cdot \mathrm{kPa}^{-1}$, respectively [12]. Manrique et al. reported the slope to be -1.48 $\mathrm{g} \cdot \mathrm{MJ}^{-1} \cdot \mathrm{kPa}^{-1}$ for potato (Solanum tuberosum L.) [13]. Summarizing data from the literature for wheat and barley (Hordeum vulgare L.) and assuming similar RUE for both species, Kemanian et al. estimated that RUE based on intercepted solar radiation was reduced with increasing VPD with a slope of $-0.53 \mathrm{~g} \cdot \mathrm{MJ}^{-1} \cdot \mathrm{kPa}^{-1}$ [14]. The effect of VPD on RUE of maize and sorghum was summarized by Kiniry et al. [15]. These authors estimated the effect of VPD by means of carbon dioxide exchange rate response to VPD and found that for all the conditions reported, increased VPD resulted in a reduction in RUE.

Considering the response of crop growth to environment, it was hypothesized that radiation use efficiency of cotton differs among geographic locations due to differences in environmental parameters such as vapor pressure deficit. The objective of the study was to determine and compare the radiation use efficiency of cotton in the contrasting cotton production environments of Arkansas and California.

\section{Materials and Methods}

The effect of environment on the radiation use efficiency of cotton was studied in 2006 and 2007 at Marianna, AR (Lon Mann Cotton Research Station, University of Arkansas) $\left(34^{\circ} 5^{\prime} \mathrm{N}, 90^{\circ} 5^{\prime} \mathrm{W}\right)$ (Captina silt loam, Typical Fragiudult) and Fresno, CA (Campus Farm, California State University at Fresno) $\left(36^{\circ} 5^{\prime} \mathrm{N}, 119^{\circ} 5^{\prime} \mathrm{W}\right)$ (Ramona sandy loam, Typical Haploxeralfa). The cotton cultivar DP444BGRR (Delta and Pine Land Company, Scott, MS) was used in both locations of the study. The fertilization program was determined according to preseason soil tests and recommended rates. Weed and insect control was performed according to state recommendations at each location. The studies were furrow irrigated according to the irrigation scheduler program based on soil moisture balance and evapotranpiration in Arkansas [16], and soil water potential in California [17].

Experimental plot size was four rows, with 1-m spacing between rows, by $15 \mathrm{~m}$ long in the Arkansas location and four rows, with $0.76 \mathrm{~m}$ spacing between rows, by 15 $\mathrm{m}$ long in the California location. Data were collected from 10 plots in each location.

Radiation use efficiency was estimated for the period between the pinhead square (PHS) stage of growth and three weeks after first flower $(\mathrm{FF}+3)$, by the slope of the increase in dry matter over the accumulated intercepted radiation, when dry matter data were plotted against intercepted radiation from all plots at each location. Dry matter was determined every 10 - 15 days by collecting plant samples from $1 \mathrm{~m}^{2}$ ground area. Intercepted radiation was calculated by multiplying the incident radiation with the fraction of intercepted radiation. The fractional light interception by the crop canopy was estimated weekly, starting at PHS, by measuring photosynthetic active radiation (PAR) above and below the canopy in unobstructed sunlight, close to solar noon, using a LI191S line quantum-source quantum sensor (Li-Cor, Lincoln, NE). For each experimental plot, measurements of fractional light interception were plotted against days after PHS (day zero) and a regression line was fitted, as shown in an example in Figure 1. The quadratic equation developed for each plot was used to estimate fractional light interception for each day of the measuring period.

Maximum and minimum temperature, maximum and minimum relative humidity, and photosynthetically active radiation were recorded daily in each location, by a weather station in close proximity to the field. A WatchDog 2475 weather station (Spectrum Technologies Inc., Plainfield, IL) was used in the Arkansas location, and a CR-10 station (Cambell Scientific Inc., Logan, UT) was used in the California location.

Vapor pressure deficit was calculated for each day of the measurement periods as the difference between the saturation $\left(e_{s}\right)$ and actual $\left(e_{a}\right)$ vapor pressure [18]. The saturation vapor pressure was computed using the equation:

$$
\mathrm{e}^{\mathrm{o}}(\mathrm{T})=0.6108 \exp \left[\frac{17.27 \cdot \mathrm{T}}{\mathrm{T}+237.3}\right]
$$

where $\mathrm{e}^{\mathrm{o}}(\mathrm{T})$ the saturation vapor pressure at the air temperature $\mathrm{T}(\mathrm{kPa}), \mathrm{T}$ the air temperature $\left({ }^{\circ} \mathrm{C}\right)$, and $\exp [\cdot \cdot]$ the base of natural logarithm (2.7183) raised to the power of $[\cdot \cdot]$. Mean daily saturation vapor pressure was estimated by the equation:

$$
\mathrm{e}_{\mathrm{s}}=\frac{\mathrm{e}^{\mathrm{o}}\left(\mathrm{T}_{\text {max }}\right)+\mathrm{e}^{\mathrm{o}}\left(\mathrm{T}_{\text {min }}\right)}{2}
$$

The actual vapor pressure was calculated using maximum and minimum relative humidity values:

$$
\mathrm{e}_{\mathrm{a}}=\frac{\mathrm{e}^{\mathrm{o}}\left(\mathrm{T}_{\min }\right) \frac{\mathrm{RH}_{\max }}{100}+\mathrm{e}^{\mathrm{o}}\left(\mathrm{T}_{\max }\right) \frac{\mathrm{RH}_{\text {min }}}{100}}{2}
$$

where $e_{a}$ the actual vapor pressure $(\mathrm{kPa}), \mathrm{e}^{\mathrm{o}}\left(\mathrm{T}_{\min }\right)$ the saturation vapor pressure at daily minimum temperature $(\mathrm{kPa}), \mathrm{e}^{\mathrm{o}}\left(\mathrm{T}_{\max }\right)$ the saturation vapor pressure at daily maximum temperature $(\mathrm{kPa}), \mathrm{RH}_{\min }$ the minimum relative humidity (\%), and $\mathrm{RH}_{\max }$ the maximum relative humidity (\%).

Statistical analysis was performed with the JMP 6 software (SAS Institute Inc., Cary, NC). Effect of location was tested with analysis of variance (ANOVA) at $\alpha$ 
$\leq 0.05$. Means were separated with Student's t-test $(\alpha \leq$ $0.05)$. Regression analysis was used to test differences in productivity of dry matter and radiation use efficiency between locations.

\section{Results and Discussion}

Mean values of maximum $\left(\mathrm{T}_{\max }\right)$ and minimum $\left(\mathrm{T}_{\min }\right)$ temperature, mean relative humidity $(\mathrm{RH})$, incident photosynthetically active radiation (PAR), and vapor pressure deficit (VPD) for the period between PHS of growth and $\mathrm{FF}+3$ are summarized for the two locations and the two years of the study in Table 1. Higher minimum temperature and relative humidity were observed at Arkansas compared to California. On the other hand, the Arkansas location had lower maximum temperature, incident photosynthetically active radiation, and vapor pressure deficit. Daily values of vapor pressure deficit are presented in Figure 2(a) for 2006 and Figure 2(b) for 2007, and show the higher VPD in California compared to Arkansas throughout the period of measurements.

Heat unit accumulation for the period between the pinhead square stage of growth and three weeks after first flower were similar for the two locations of the study in both 2006 and 2007 (Table 2). During the period that data were collected, the cotton crop canopy intercepted significantly higher amounts of photosynthetically active radiation in California than in Arkansas for both years of the study (Table 2). Similarly, the cotton crop in California produced significantly more dry matter for the same period (Table 2). Regression analysis showed that daily productivity of dry matter was significantly higher for California compared to Arkansas (Table 2).

Radiation use efficiency of cotton in 2006 did not significantly differ between locations of the study $(\mathrm{P}=$ 0.266 ) and was calculated at $1.78 \mathrm{~g} \cdot \mathrm{MJ}^{-1} \mathrm{PAR}$ for $\mathrm{Ar}$ kansas and $1.34 \mathrm{~g} \cdot \mathrm{MJ}^{-1}$ PAR for California (Figure 3;

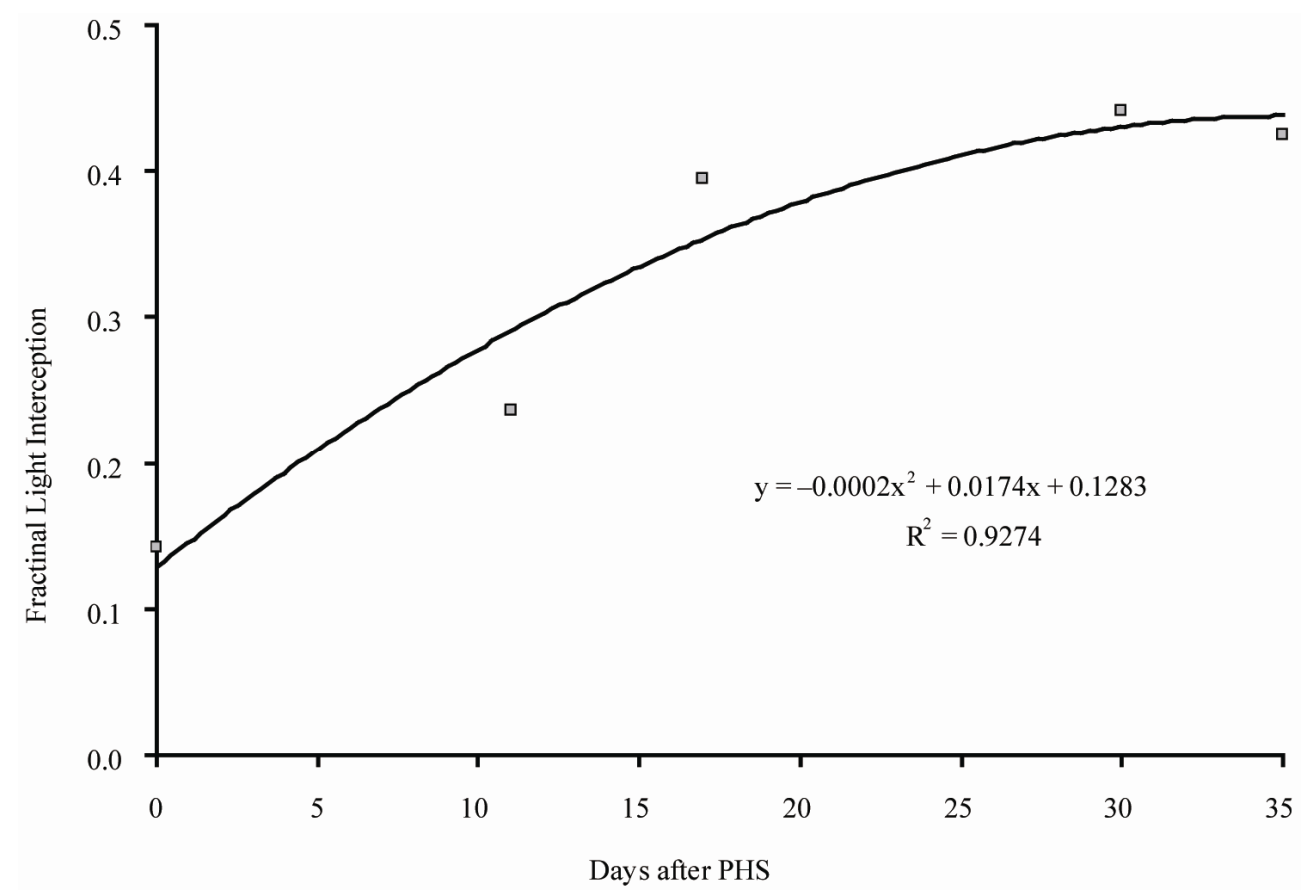

Figure 1. An example of calculating daily fractional light interception. For each experimental plot, measurements of fractional light interception were plotted against days after PHS (day zero) and a regression line was fitted, as shown above. The quadratic equation developed for each plot was used to estimate fractional light interception for each day of the measuring period.

Table 1. Mean daily values of weather data recorded at the two locations of the study between PHS and FF+3.

\begin{tabular}{|c|c|c|c|c|c|c|c|c|c|c|}
\hline \multirow{2}{*}{ Location } & \multicolumn{2}{|c|}{$\mathrm{T}_{\max }$} & \multicolumn{2}{|c|}{$\mathrm{T}_{\min }$} & \multicolumn{2}{|c|}{$\mathrm{RH}$} & \multicolumn{2}{|c|}{ PAR } & \multicolumn{2}{|c|}{ VPD } \\
\hline & 2006 & 2007 & 2006 & 2007 & 2006 & 2007 & 2006 & 2007 & 2006 & 2007 \\
\hline & \multicolumn{2}{|c|}{$\left({ }^{\circ} \mathrm{C}\right)$} & \multicolumn{2}{|c|}{$\left({ }^{\circ} \mathrm{C}\right)$} & \multicolumn{2}{|c|}{$(\%)$} & \multicolumn{2}{|c|}{$\left(\mathrm{MJ} \cdot \mathrm{m}^{-2}\right)$} & \multicolumn{2}{|c|}{$(\mathrm{kPa})$} \\
\hline Arkansas & 33.1 & 32.5 & 21.3 & 21.3 & 67.5 & 75.5 & 10.12 & 8.75 & 1.68 & 1.35 \\
\hline California & 37.7 & 34.2 & 19.3 & 15.9 & 43.7 & 44.9 & 13.30 & 12.91 & 2.92 & 2.49 \\
\hline P-value & $<0.0001$ & $<0.0001$ & 0.002 & $<0.0001$ & $<0.0001$ & $<0.0001$ & $<0.0001$ & $<0.0001$ & $<0.0001$ & 0.020 \\
\hline
\end{tabular}




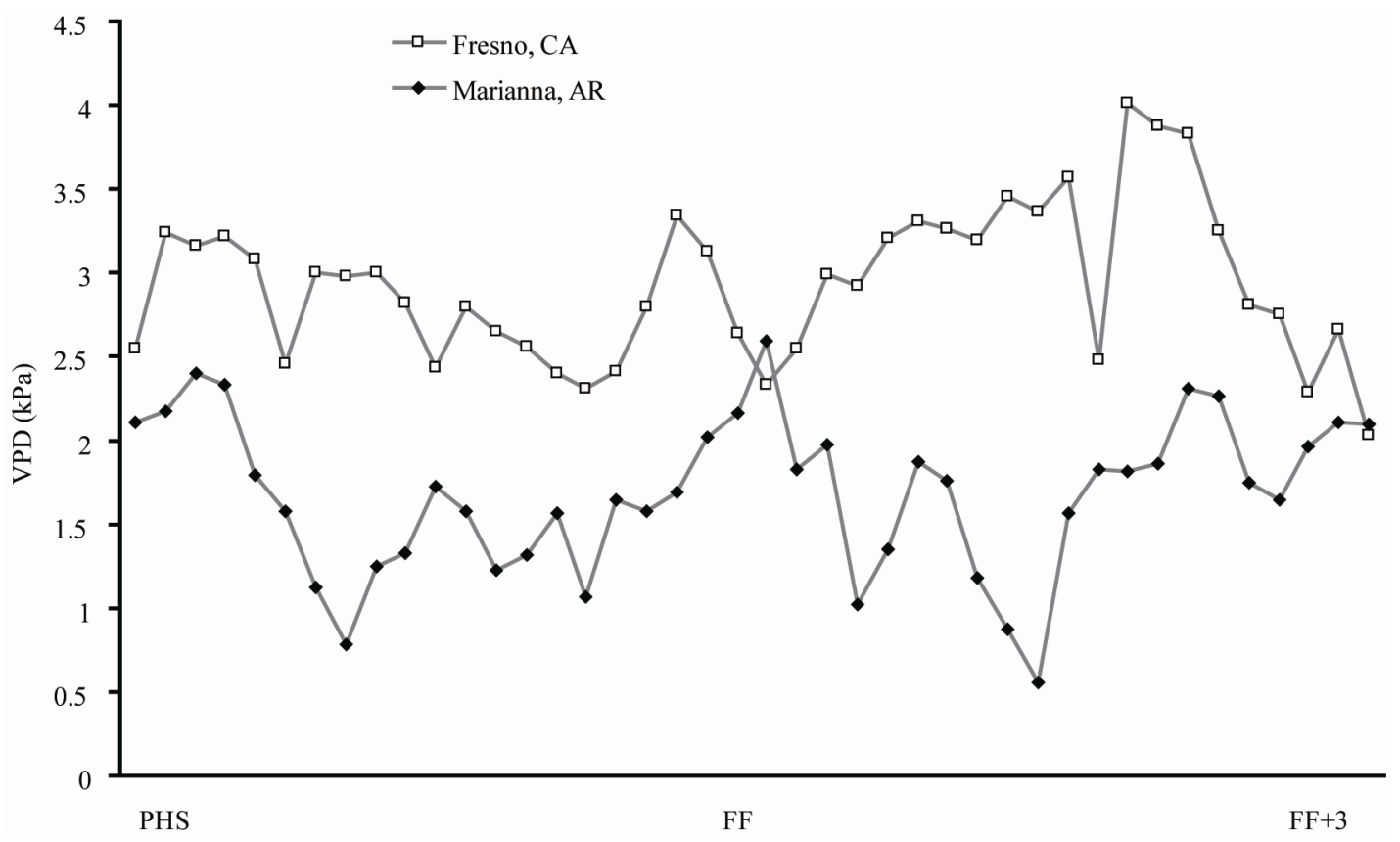

(a)

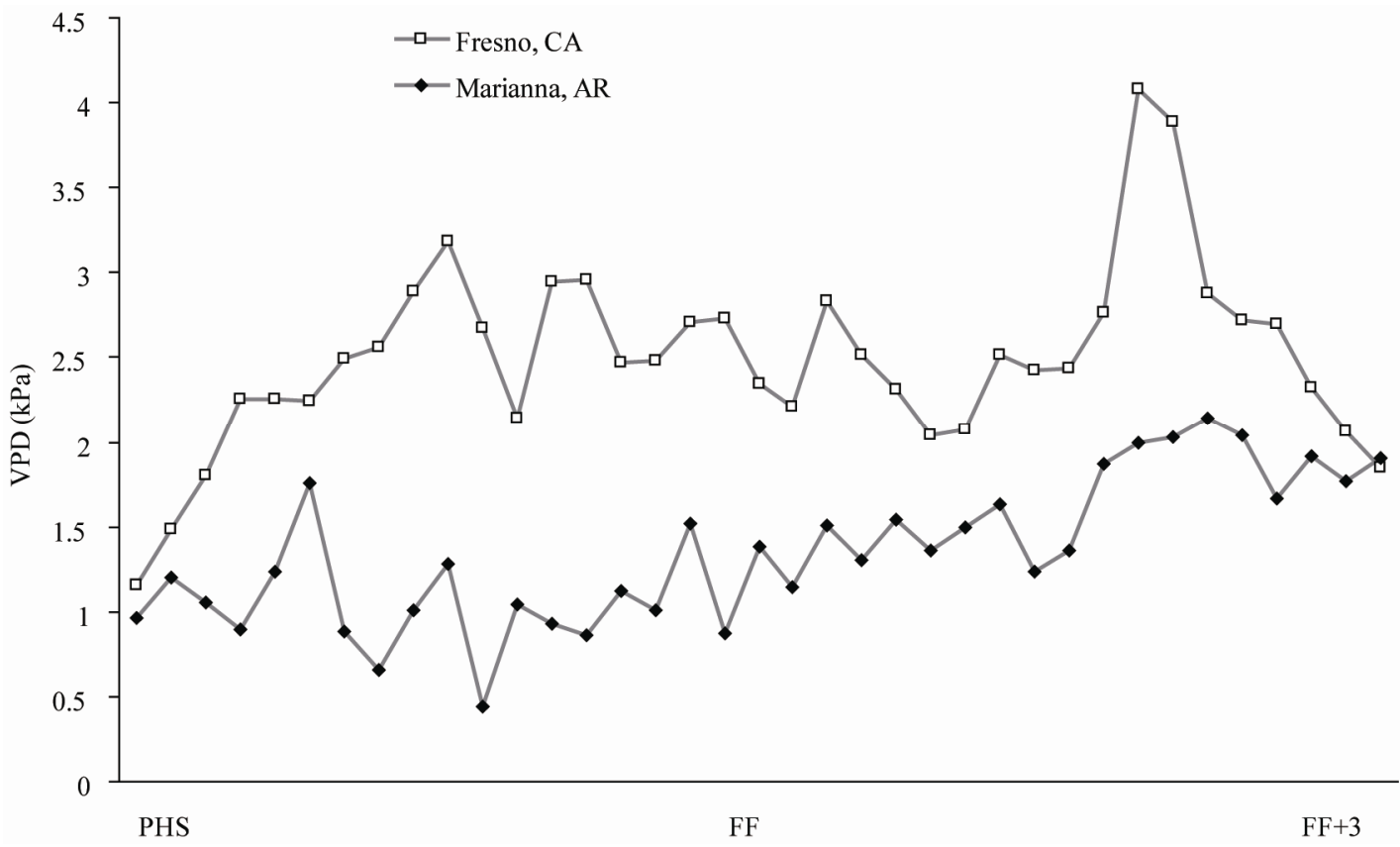

(b)

Figure 2. Daily mean values of vapor pressure deficit estimated for the two locations of the study between PHS and FF+3, for 2006 (a) and 2007 (b).

Appendices 1). In 2007, values of radiation use efficiency differed significantly $(\mathrm{P}=0.045)$ for Arkansas and California and were estimated at 2.28 and $1.80 \mathrm{~g} \cdot \mathrm{MJ}^{-1} \mathrm{PAR}$, respectively (Figure 3; Appendices 2). When the data were analyzed statistically across years no significant interaction between radiation use efficiency and year was detected $(\mathrm{P}=0.925)$. Therefore, mean values of radiation use efficiency were calculated over years. The statistical analysis revealed a significant location effect $(\mathrm{P}=0.033)$ with Arkansas having higher radiation use efficiency than California. The values of radiation use efficiency for the Arkansas and California locations were 2.06 and 1.52 $\mathrm{g} \cdot \mathrm{MJ}^{-1} \mathrm{PAR}$ respectively (Figure 3 ).

\section{Discussion}

The values of radiation use efficiency estimated in this 


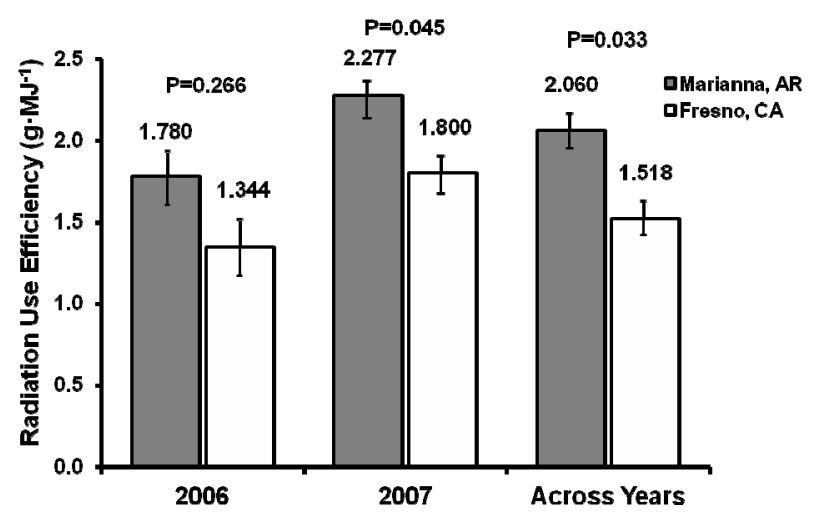

Figure 3. Radiation use efficiency of cotton grown in Marianna, AR and Fresno, CA. P-values, radiation use efficiency values and \pm 1 std error bars are shown.

study are similar to previous reports for cotton [3-5]. The cotton crop grown in Arkansas appeared to utilize the intercepted radiation more efficiently $(+36 \%)$ compared to California (Figure 3). However, the California envi- ronment was found to be more productive, accumulating dry matter at a higher rate over the period of the study (Table 1). The higher amount of dry matter ( $+46 \%)$ produced in California can be explained by the higher amount of incident and more intercepted radiation $(+73 \%)$ in California compared to Arkansas. This is also reflected in the higher yields experienced in California (Cotton Economic Review, National Cotton Council of America, Memphis, TN).

Any environmental factor that limits crop growth should reduce radiation use efficiency. However, for sorghum, maize, and sunflower radiation use efficiency could not be related to incident solar radiation and temperature [2]. Similar to the effect of vapor pressure deficit on radiation use efficiency described for crops such as sorghum [12], potato (Manrique et al., 1991), and wheat and barley (Kemanian et al., 2004), increasing vapor pressure deficit decreased radiation use efficiency of cotton by a slope of $-0.46 \mathrm{~g} \cdot \mathrm{MJ}^{-1} \cdot \mathrm{kPa}^{-1}$ (Figure 4). A parameter that needs to be addressed in future research in-

Table 2. Heat unit accumulation, dry matter production, intercepted radiation and daily dry matter productivity of the cotton crop at the two locations of the study between PHS and FF+3.

\begin{tabular}{|c|c|c|c|c|c|c|c|c|}
\hline \multirow{3}{*}{ Location } & \multicolumn{2}{|c|}{ Heat Units } & \multicolumn{2}{|c|}{ Intercepted Radiation } & \multicolumn{2}{|c|}{ Dry Matter } & \multicolumn{2}{|c|}{ Productivity } \\
\hline & 2006 & 2007 & 2006 & 2007 & 2006 & 2007 & 2006 & 2007 \\
\hline & \multicolumn{2}{|c|}{-} & \multicolumn{2}{|c|}{$\left(\mathrm{MJ} \cdot \mathrm{m}^{-2}\right)$} & \multicolumn{2}{|c|}{$\left(\mathrm{g} \cdot \mathrm{m}^{-2}\right)$} & \multicolumn{2}{|c|}{$\left(\mathrm{g} \cdot \mathrm{m}^{-2} \cdot \mathrm{day}^{-1}\right)$} \\
\hline Arkansas & 902 & 754 & 270.1 & 249.2 & 475.8 & 583.2 & 11.57 & 16.43 \\
\hline California & 982 & 718 & 464.7 & 433.4 & 730.9 & 813.5 & 17.40 & 20.38 \\
\hline P-value & - & - & $<0.0001$ & $<0.0001$ & 0.0014 & 0.0006 & 0.0004 & 0.0070 \\
\hline
\end{tabular}

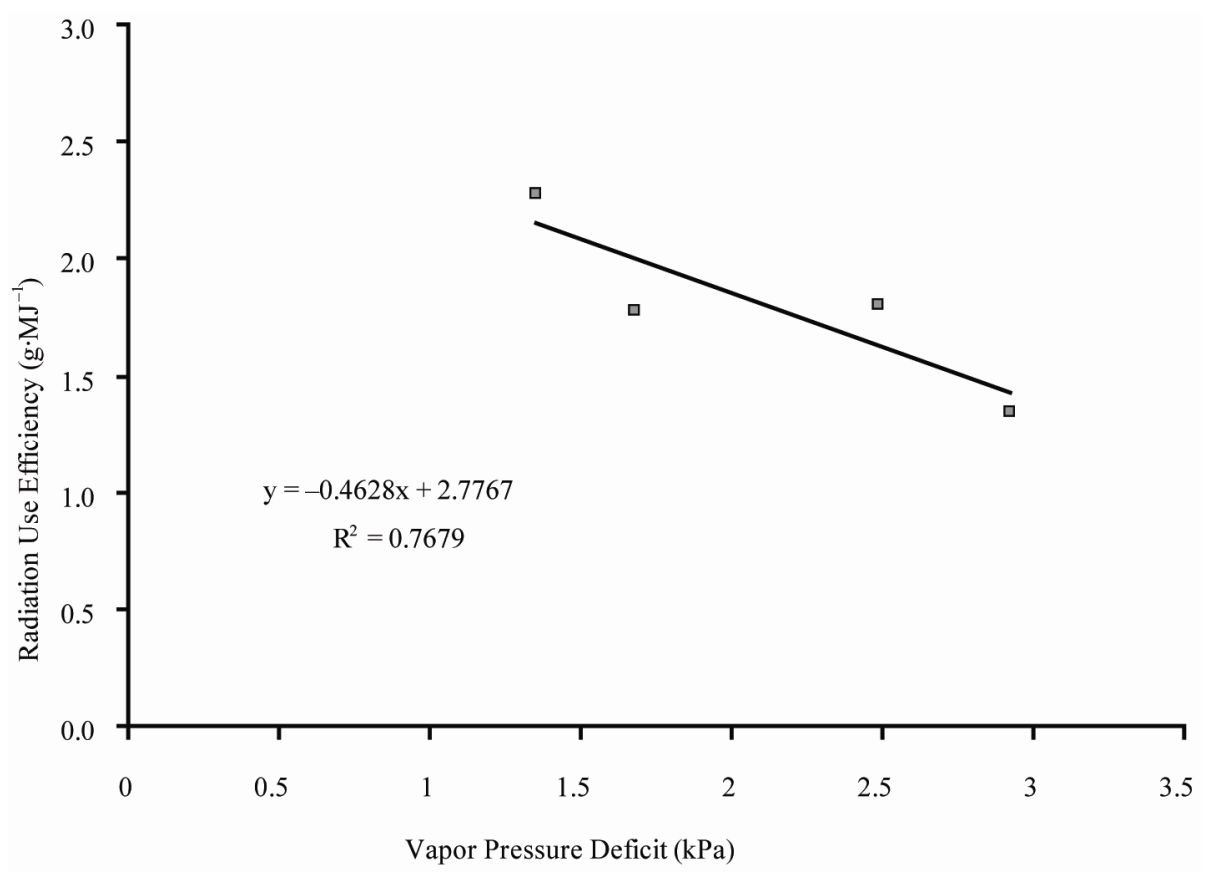

Figure 4. Relationship between radiation use efficiency and vapor pressure deficit for cotton. Data from Marianna, AR and Fresno, CA in 2006 and 2007. 
volving radiation use efficiency across environments is the ratio of direct to diffuse incident radiation. Theoretical approaches by Sinclair et al. [9] and experimental data by Bange et al. [8] have shown an increase in radiation use efficiency of soybean, maize, and sunflower when the total amount of radiation decreased and the portion of diffuse radiation increased. Differences in radiation use efficiency between locations could be more profound when comparing areas of high and low relative humidity, commonly associated with differences in the radiation environment.

In this study, only the effect of increasing vapor pressure deficit on radiation use efficiency of cotton was evaluated. The results of this study support our hypothesis that radiation use efficiency of cotton differs among geographic locations due to differences on vapor pressure deficit. To the authors knowledge this is the first study demonstrating the effect of vapor pressure deficit on radiation use efficiency of cotton. These results are in accordance to previous data reported in crops other than cotton.

\section{REFERENCES}

[1] J. N. Gallagher and P. V. Biscoe, "Radiation Absorption, Growth and Yield of Cereals," Journal of Agricultural Science, Vol. 91, No. 1, 1978, pp. 47-60. doi:10.1017/S0021859600056616

[2] J. R. Kiniry, C. A. Jones, J. C. O'Toole, R. Blanchet, M. Cabelguenne and D. A. Spanel, "Radiation-Use Efficiency in Biomass Accumulation Prior to Grain-Filling for Five Grain-Crop Species," Field Crops Research, Vol. 20, No. 1, 1989, pp. 51-64. doi:10.1016/0378-4290(89)90023-3

[3] V. O. Sadras and L. J. Wilson, "Growth Analysis of Cotton Crop Infested with Spider Mites: I. Light Interception and Radiation Use Efficiency," Crop Science, Vol. 37, No. 2, 1997, pp. 481-491. doi:10.2135/cropsci1997.0011183X003700020029x

[4] W. D. Rosenthal and T. J. Gerik, "Radiation Use Efficiency among Cotton Cultivars," Agronomy Journal, Vol. 83, No. 4, 1991, pp. 655-658. doi:10.2134/agronj1991.00021962008300040001x

[5] P. J. Pinter, B. A. Kimball, J. R. Mauney, G. R. Hendrey, K. F. Lewin and J. Nagy, "Effects of Free-Air Carbon Dioxide Enrichment on PAR Absorption and Conversion Efficiency in Cotton," Agricultural and Forest Meteorology, Vol. 70, No. 1-4, 1994, pp. 209-230. doi:10.1016/0168-1923(94)90059-0

[6] A. C. Bibi, D. M. Oosterhuis and E. D. Gonias, "Photosynthesis, Quantum Yield of Photosystem II and Membrane Leakage as Affected by High Temperatures in Cotton Genotypes," Journal of Cotton Science, Vol. 12, 2008, pp. 150-159.
[7] M. J. Bell, G. C. Wright and G. L. Hammer, "Night Temperature Affects Radiation-Use Efficiency in Peanut," Crop Science, Vol. 32, No. 6, 1992, pp. 1329-1335. doi:10.2135/cropsci1992.0011183X003200060005x

[8] M. P. Bange, G. L. Hammer and K. G. Rickert, "Effect of Radiation Environment on Radiation Use Efficiency and Growth of Sunflower," Crop Science, Vol. 37, No. 4, 1997, pp. 1208-1214. doi:10.2135/cropsci1997.0011183X003700040030x

[9] T. R. Sinclair, T. Shiraiwa and G. L. Hammer, "Variation in Crop Radiation-Use Efficiency with Increasing Diffuse Radiation," Crop Science, Vol. 32, No. 5, 1992, pp. 12811284. doi:10.2135/cropsci1992.0011183X003200050043x

[10] J. J. Prenger and P. P. Ling, "Greenhouse Condensation Control. Understanding and Using Vapor Pressure Deficit (VPD)," Fact Sheet AEX-800, Ohio State University Extension, 2006.

http://ohioline.osu.edu/aex-fact/0804.html

[11] J. E. Leach, "Some Effects of Air Temperature and Humidity on Crop and Leaf Photosynthesis, Transpiration and Resistance to Gas Transfer," Annals of Applied Biology, Vol. 92, No. 2, 1979, pp. 287-297. doi:10.1111/j.1744-7348.1979.tb03876.x

[12] C. O. Stöckle and J. R. Kiniry, "Variability in Crop Radiation Use Efficiency Associated with Vapor-Pressure Deficit," Field Crops Research, Vol. 25, No. 3-4, 1990, pp. 171-181. doi:10.1016/0378-4290(90)90001-R

[13] L. A. Manrique, J. R. Kiniry, T. Hodges and D. S. Axness, "Dry Matter Production and Radiation Interception of Potato," Crop Science, Vol. 31, No. 4, 1991, pp. 10441049. doi:10.2135/cropsci1991.0011183X003100040040x

[14] A. R. Kemanian, C. O. Stöckle and D. R. Huggins, "Variability of Barley Radiation-Use Efficiency," Crop Science, Vol. 44, No. 5, 2004, pp. 1662-1672. doi:10.2135/cropsci2004.1662

[15] J. R. Kiniry, J. A. Landivar, M. Witt, T. J. Gerik, J. Cavero and L. J. Wade, "Radiation-Use Efficiency Response to Vapor Pressure Deficit for Maize and Sorghum," Field Crops Research, Vol. 56, No. 3, 1998, pp. 265-270. doi:10.1016/S0378-4290(97)00092-0

[16] J. Cahoon, J. Ferguson, D. Edwards and P. Tacker, “A Microcomputer-Based Irrigation Scheduler for the Humid Mid-South Region," American Society of Agricultural Engineers, Vol. 6, 1990, pp. 289-295.

[17] J. S. Hake, D. W. Grimes, K. D. Hake, T. A. Kerby, D. J. Munier and L. J. Zelinski, "Irrigation Scheduling," In: J. S. Hake, T. A. Kerby and K. D. Hake, Eds., Cotton Production Manual, University of California, Division of Agriculture and Natural Resources, Pub. 3352, 1996, pp. 228-247.

[18] R. G. Allen, L. S. Pereira, D. Raes and M. Smith, "Crop Evapotranspiration: Guidelines for Computing Crop Water Requirements," FAO Irrigation and Drainage Paper No. 56, Rome, 1998. 